OPEN ACCESS

Edited by:

Kenneth Boheler

Johns Hopkins University,

United States

Reviewed by:

Ellen Poon

The University of Hong Kong,

Hong Kong

Praphulla C. Shukla,

Indian Institute of Technology

Kharagpur, India

*Correspondence:

Katja Lakota

katja.lakota@guest.arnes.si

Mojca Frank-Bertoncelj

mojca.frank@usz.ch

tThese authors have contributed equally to this work

Specialty section:

This article was submitted to Cardiovascular Biologics and

Regenerative Medicine,

a section of the journal

Frontiers in Cardiovascular Medicine

Received: 14 December 2018

Accepted: 16 April 2019

Published: 16 May 2019

Citation:

Burja B, Kuret T, Janko T, Topalović $D$,

Živković L, Mrak-Poljšak K, Spremo-Potparević B, Žigon $P$,

Distler O, Čučnik S, Sodin-Semrl S,

Lakota K and Frank-Bertoncelj $M$

(2019) Olive Leaf Extract Attenuates

Inflammatory Activation and DNA Damage in Human Arterial Endothelial

Cells. Front. Cardiovasc. Med. 6:56. doi: $10.3389 /$ fCvm.2019.00056

\section{Olive Leaf Extract Attenuates Inflammatory Activation and DNA Damage in Human Arterial Endothelial Cells}

Blaž Burja ${ }^{1,2}$, Tadeja Kuret ${ }^{1,3}$, Tea Janko ${ }^{4}$, Dijana Topalović ${ }^{5}$, Lada Živković ${ }^{5}$, Katjuša Mrak-Poljšak ${ }^{1}$, Biljana Spremo-Potparević ${ }^{5}$, Polona Žigon ${ }^{1}$, Oliver Distler ${ }^{2}$, Saša Čučnik ${ }^{1,3}$, Snezna Sodin-Semrl ${ }^{1,4}$, Katja Lakota ${ }^{1,4 *}$ and Mojca Frank-Bertoncelj ${ }^{2 * t}$

\begin{abstract}
${ }^{1}$ Department of Rheumatology, University Medical Centre, Ljubljana, Slovenia, ${ }^{2}$ Department of Rheumatology, Center of Experimental Rheumatology, University Hospital Zurich, Zurich, Switzerland, ${ }^{3}$ Chair of Clinical Biochemistry, Faculty of Pharmacy, University of Ljubljana, Ljubljana, Slovenia, ${ }^{4}$ Faculty of Mathematics, Natural Science and Information Technology, University of Primorska, Koper, Slovenia, ${ }^{5}$ Department of Pathobiology, Faculty of Pharmacy, University of Belgrade, Belgrade, Serbia
\end{abstract}

Olive leaf extract (OLE) is used in traditional medicine as a food supplement and as an over-the-counter drug for a variety of its effects, including anti-inflammatory and anti-atherosclerotic ones. Mechanisms through which OLE could modulate these pathways in human vasculature remain largely unknown. Serum amyloid A (SAA) plays a causal role in atherosclerosis and cardiovascular diseases and induces pro-inflammatory and pro-adhesive responses in human coronary artery endothelial cells (HCAEC). Within this study we explored whether OLE can attenuate SAA-driven responses in HCAEC. HCAEC were treated with SAA $(1,000 \mathrm{nM})$ and/or OLE $(0.5$ and $1 \mathrm{mg} / \mathrm{ml})$. The expression of adhesion molecules VCAM-1 and E-selectin, matrix metalloproteinases (MMP2 and MMP9) and microRNA 146a, let-7e, and let-7g (involved in the regulation of inflammation) was determined by qPCR. The amount of secreted IL-6, IL-8, MIF, and GRO- $\alpha$ in cell culture supernatants was quantified by ELISA. Phosphorylation of $\mathrm{NF}-\mathrm{kB}$ was assessed by Western blot and DNA damage was measured using the COMET assay. OLE decreased significantly released protein levels of IL-6 and IL-8, as well as mRNA expression of E-selectin in SAA-stimulated HCAEC and reduced MMP2 levels in unstimulated cells. Phosphorylation of NF-kB (p65) was upregulated in the presence of SAA, with OLE significantly attenuating this SAA-induced effect. OLE stabilized SAA-induced upregulation of microRNA-146a and let-7e in HCAEC, suggesting that OLE could fine-tune the SAA-driven activity of NF-кB by changing the microRNA networks in HCAEC. SAA induced DNA damage and worsened the oxidative DNA damage in HCAEC, whereas OLE protected HCAEC from SAA- and $\mathrm{H}_{2} \mathrm{O}_{2}$-driven DNA damage. OLE significantly attenuated certain pro-inflammatory and pro-adhesive responses and decreased DNA damage in HCAEC upon stimulation with SAA. The reversal of SAA-driven endothelial activation by OLE might contribute to its anti-inflammatory and anti-atherogenic effects in HCAEC.

Keywords: OLE, SAA, HCAEC, inflammation, atherosclerosis, microRNA, DNA damage 


\section{INTRODUCTION}

Cardiovascular diseases, including coronary artery disease, are the leading cause of death globally, with atherosclerosis being the most common underlying reason for cardiovascular morbidity and mortality. In addition, systemic inflammation (present in a number of chronic diseases, including metabolic syndrome and rheumatoid arthritis) drives accelerated atherosclerosis (1) and patients with these diseases are at risk for developing atherosclerosis and its complications. Serum amyloid A (SAA), a major acute phase protein, is increased in chronic inflammatory diseases and coronary artery disease $(2,3)$. SAA was shown to be an early causal agent for atherosclerosis in animal models $(4,5)$. Serum levels of SAA have been reported to correlate with severity of atherosclerosis $(6,7)$ and have been utilized as a predictor of mortality following acute myocardial infarction $(8,9)$. In addition, SAA was shown to enhance monocyte and lymphocyte recruitment, directly stimulating foam cell formation, associating with HDL/LDL particles and compromising reverse cholesterol transport, among other processes (7). Furthermore, SAA was reported to induce matrix metalloproteinases (MMP), as well as increase biglycan synthesis and influence retention of lipoproteins by vascular proteoglycans (10). Early on, Ridker reported that even chronic low grade inflammation may lead to atherosclerosis and the development of cardiovascular diseases (11), emphasizing the importance of measuring systemic inflammatory markers, such as SAA.

Atherosclerotic lesions typically develop in coronary arteries and the activation of endothelium represents one of the crucial early steps in the development of atherosclerotic lesions in the coronary arterial system. Human coronary artery endothelial cells (HCAEC) therefore represent a suitable in vitro model to study the mechanisms of endothelial activation and atherosclerosis. HCAEC strongly respond to stimulation with SAA, activating a number of pro-inflammatory, proadhesive and pro-coagulant responses, as measured by increased expression of interleukin 6 (IL-6), interleukin 8 (IL-8), vascular cell adhesion molecule (VCAM1) and tissue factor (12). Elevated amounts of systemic SAA in patients with coronary artery disease may represent a potential pathophysiological link between inflammation, lipoprotein metabolism, oxidative stress and the development of atherosclerosis (2). DNA damage is emerging as a crucial player in accelerating the development and progression of atherosclerosis. In addition to microRNAs, which are important regulators of cellular processes leading to atherosclerosis (13-15), DNA damage has been reported to be a biomarker of atherosclerosis in monocytes (16). There is a lack of information concerning whether DNA damage and alterations in microRNA networks accompany or contribute to the SAA-driven endothelial activation.

Olive oil represents the basis of atheroprotective effects of the Mediterranean diet, and olive leaf extract (OLE) contains a much higher concentration of active polyphenol compounds compared with extra virgin olive oil (17). OLE from the olive tree (Olea europaea L.) is used as a food supplement or as an over-the-counter drug for a variety of benefits including its anti-arrhythmic, anti-atherosclerotic (18), anti-hypertensive, antioxidant, anti-tumor, anti-proliferative, anti-inflammatory $(19,20)$, and anti-fibrotic $(20,21)$ effects. The $80 \%$ alcoholic extract of olive leaves has also been included in the European Pharmacopeia (Ph. Eur.) based on a subset of its protective properties (20). The polyphenols of the olive tree activated major anti-oxidant pathways, including transcription factor $\mathrm{Nrf2}$, as well as AMPK, IGF/Akt, and mTOR, thereby acting similarly to caloric restriction mimickers (20).

Dry OLE is rich in water-soluble phenolic compounds, specifically secoiridoid oleuropein (17\%), whereas the remaining compounds [apigenine-7-O-glucoside, luteolin-7-O-glucoside, quercetin, and caffeic acid] are present in substantially smaller amounts $[<0.1 \%]$ (22). Secoiridoid oleuropein consists of a polyphenolic molecule known as hydroxytyrosol, bound to elenolic acid and a glucose molecule. OLE and its compounds can repress the expression of a number of pro-inflammatory genes. Specifically, oleuropein decreased the expression of IL6 and IL-1 $\beta$ in colon during DSS-induced colitis (23) and in LPS-stimulated macrophages (Raw264.7) (24). Peripheral blood mononuclear cells (PBMC) from healthy individuals, who consumed OLE on a single occasion, expressed less IL-8 when stimulated ex vivo with LPS (25), and serum IL-8 levels decreased in hypertensive individuals who consumed OLE for 6 weeks (26). IL-8 was also one of the most downregulated genes in PBMC from healthy subjects who consumed OLE for 8 weeks. The major contributors to these effects were downregulation of the arachidonic acid and NF- $\mathrm{KB}$ pathways by OLE (27). The inflammatory molecules MCP-1, VCAM-1, and TNF- $\alpha$ were down-regulated in thoracic aorta of rabbits on a high lipid diet supplemented with OLE, as compared to a high lipid diet alone (18). Oleuropein and hydroxytyrosol, the constituents of OLE, inhibited the expression of both VCAM-1 and ICAM-1 in human umbilical vein endothelial cells, further accompanied by a decreased activation of NF-KB and AP- 1 and reduced monocyte adhesion (28). These studies suggest that OLE could affect proinflammatory and pro-adhesive cellular responses during the atherosclerotic process in the arterial wall.

In our present work, we show that OLE significantly attenuated the SAA-driven pro-inflammatory and pro-adhesive responses of HCAEC and modulated SAA-induced miR-146a and let-7e. OLE decreased SAA-induced phosphorylation of NF- $\mathrm{KB}$ and protected endothelial cells from SAAinduced DNA damage. This suggests that OLE might exhibit multiple athero-protective effects in coronary arterial vasculature.

\section{MATERIALS AND METHODS}

\section{Materials}

Lyophilized human recombinant SAA (Peprotech EC Ltd., London, UK) was reconstituted according to manufacturer's instructions to stock concentration and stored until usage at -20 or $-80^{\circ} \mathrm{C}$. The final concentration of SAA in experiments was $1,000 \mathrm{nM}$. Dry OLE EFLA ${ }^{\circledR} 943$ (Frutarom Switzerland Ltd., Wadenswil, Switzerland) was originally manufactured by applying an ethanol extraction procedure $(80 \% \mathrm{~m} / \mathrm{m})$ from the dried leaves of olive tree, standardized to $16-24 \%$ of oleuropein. 
Dry OLE powder was diluted in phosphate buffered saline (PBS) to a final concentration of $0.1 \mathrm{~g} / \mathrm{ml}$, unless otherwise indicated.

\section{Cell Culture}

HCAEC from four different donors were purchased from Lonza (Walkesville, Maryland, USA). The cells were plated onto $25 \mathrm{~cm}^{2}$ flasks and 6 or 24 well-plates (TPP, Trasadigen, Switzerland) and cultured at $37^{\circ} \mathrm{C}$ in a humidified atmosphere at $5 \% \mathrm{CO}_{2}$. HCAEC were grown in EGM-2M medium (CambrexBioScience, Walkesville, Maryland, USA) containing $5 \%$ fetal bovine serum. For experiments, subconfluent cell cultures were used between passages 4 and 6 in serum-free medium, with pretreatment of OLE for $45 \mathrm{~min}$, followed by addition of SAA for $24 \mathrm{~h}$, unless otherwise indicated. Prior to experiments, cells were incubated in serum-free medium for $2 \mathrm{~h}$.

\section{RNA Isolation and Reverse Transcription Polymerase Chain Reaction Analysis}

Prior to reverse transcription polymerase chain reaction (RT-PCR), total RNA from endothelial cell cultures was isolated using Total RNA Isolation System RNeasyPlus Micro (Qiagen, Germany), following manufacturer's instructions. The purity and amount of RNA were determined by measuring the $\mathrm{OD}$ at a ratio of 260 to $280 \mathrm{~nm}$. One microgram of total RNA was transcribed into cDNA by Reverse Transcription System (Promega, Madison, WI, USA). For microRNA measurements, 5 ng of total RNA was reverse-transcribed using the TaqMan ${ }^{\circledR}$ MicroRNA Reverse Transcription Kit and miRNA-specific RT primers (Applied Biosystems).

\section{Real Time PCR}

The expression of mRNA was measured with real time PCR ABI Step One (Applied Biosystems, Foster City, CA, USA) using Kapa Sybr master mix (Sigma-Aldrich, Germany), forward and reverse primers (200 $\mathrm{nM}$ each) and $10 \mathrm{ng}$ cDNA per well. Primer sequences and conditions for RT-PCR are indicated for each primer set in Supplementary Table 1. Dissociation curves showed one peak in each PCR reaction. All experiments were performed in triplicates. GAPDH was used as an endogenous normalization control. The gene expression results were calculated with the $2^{\mathrm{Ct} \Delta \Delta}$ method. The expression of microRNAs was determined with real-time PCR $(7900 \mathrm{HT}$ Fast real-time PCR system) using TaqMan ${ }^{\circledR}$ probes and TaqMan Universal PCR Master Mix (all Applied Biosystems, Life Technologies Foster City, CA, USA). RNU48 was used as an endogenous control. Differences in microRNA expression were calculated with the ${ }_{2}^{\mathrm{Ct} \Delta \Delta}$ method.

\section{Western Blot}

Whole cell lysates were prepared from HCAEC using RIPA buffer containing Halt protease inhibitors (Pierce, Rockford, IL, USA) and phosphatase inhibitors (Cayman Chemical, Ann Arbor, MI, USA). The concentration of proteins was determined with the Bradford assay and equal amounts of proteins were loaded per gel pocket. $\alpha$-tubulin was used as a loading control.
Whole cell lysates, mixed with loading buffer, were separated on $10 \%$ SDS polyacrylamide gels and electroblotted onto nitrocellulose membranes (Whatman). Membranes were blocked for $1 \mathrm{~h}$ in $5 \%(\mathrm{w} / \mathrm{v})$ non-fat milk in TBS-T. After blocking, the membranes were probed with rabbit anti-phospho NF-кB p65 and rabbit anti-NF- $\mathrm{KB}$ p65 (S536 and E498, respectively, both at dilutions of 1:1000 Cell Signaling Technology, Danvers, MA, USA). As secondary antibodies, horseradish peroxidaseconjugated goat anti-rabbit (Cell Signaling Technology, Danvers, MA, USA) were used. Signals were detected using Femto Luminol (ThermoFisher Scientific, Hempstead, UK) with G:Box (Syngene, Cambridge,UK). Densitometry analysis of protein bands was carried out using the Fusion FX software (Vilber Lourmat). For quantification of Western blots, the levels of phosphorylated NF- $\mathrm{BB}$ were normalized to the levels of total NF-кB.

\section{Protein Detection by ELISA}

Supernatants from untreated and treated HCAEC were spun down $(300 \mathrm{~g}, 5 \mathrm{~min})$ and cell-free supernatants frozen at $-80^{\circ} \mathrm{C}$ until usage. The assays were performed using commercial ELISA kits and were done in duplicates, according to the manufacturers' instructions. IL-6 and IL-8 ELISA kits were purchased from Invitrogen (Frederick, MD, USA), while GROa and MIF quantikine ELISA were from R\&D Systems (Minneapolis, USA). Absorbance was measured at $450 \mathrm{~nm}$ with the microplate absorbance reader (Tecan, Groening, Austria). The concentrations of analytes were calculated from standard curves and multiplied by the dilution factor.

\section{Comet Assay}

HCAEC were grown in 6 well-plates. After treatment with SAA \pm OLE, cells were detached using Acutasse (Sigma Aldrich) and spun down (5 min, $300 \mathrm{~g}$ ). COMET was performed as previously described (29). Briefly, cells were resuspended in $0.067 \%$ low melting agarose (Sigma Aldrich) at $37^{\circ} \mathrm{C}$ and were layered onto slides using a coverslip. Cells from each 6 well were layered onto 4 slides and after cooling at $4^{0} \mathrm{C}$ for $10 \mathrm{~min}$, coverslips were removed. Two slides were treated with $3 \%$ $\mathrm{H}_{2} \mathrm{O}_{2}$ at $37^{\circ} \mathrm{C}$ and rinsed with PBS. The remaining two slides were immediately covered with an additional layer of $0.05 \%$ low melting agarose and were placed (after cooling) into fresh alkaline lysis buffer overnight. The lysis buffer was prepared from $89 \mathrm{ml}$ of stock solution containing $2.5 \mathrm{M} \mathrm{NaCl}, 100 \mathrm{mM}$ EDTA, $10 \mathrm{mM}$ Tris-base at $\mathrm{pH} 10,10 \mathrm{ml}$ DMSO and $1 \mathrm{ml}$ Triton-X. Slides were then immersed into cold, alkaline electrophoresis buffer $(300 \mathrm{mM} \mathrm{NaOH}, 1 \mathrm{mM}$ EDTA freshly prepared from stock $10 \mathrm{M} \mathrm{NaOH}$ and stock $200 \mathrm{mM}$ EDTA, $\mathrm{pH}$ 10) for $30 \mathrm{~min}$, after which electrophoresis was run $(30 \mathrm{~min}, 25 \mathrm{~V}, 300 \mathrm{~mA})$. This was followed by 2 repeated rinses for $10 \mathrm{~min}$ with neutralization buffer $(0.32 \mathrm{M}$ Tris base at $\mathrm{pH} 7.5)$ and water. Slides were stained with Sybr Green I, and 100 cells per slide were scored under the fluorescence microscope (Nikon eclipse TE 300 and AxioImager Z1, Carl Zeiss, 400x magnification). The average of the duplicate slides was calculated and three biological replicates were performed per experimental condition (Scheme 1). 


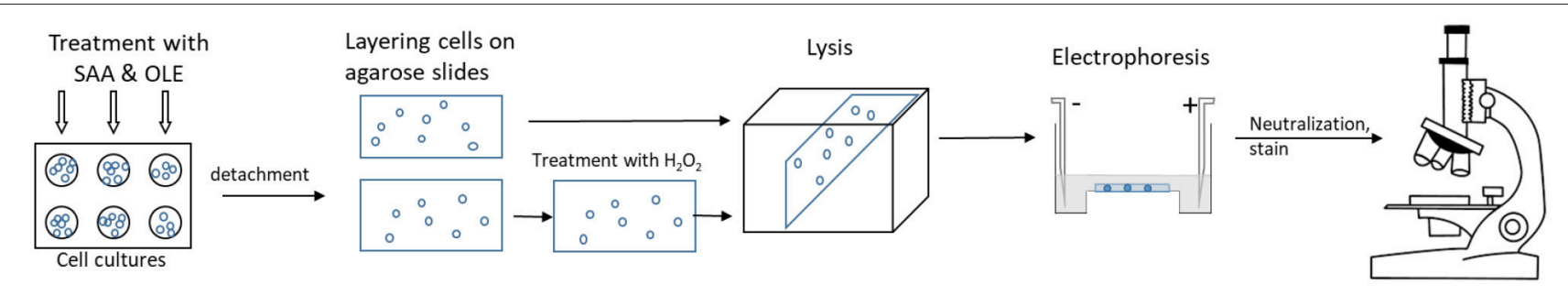

SCHEME 1 | Scheme of COMET Analysis.

\section{Statistical Analysis}

Data was presented as mean \pm standard deviation (SD), unless otherwise indicated. The differences between the various treated and control groups were analyzed with RM one way ANOVA test with Tukey's method for multiple comparisons. All data was analyzed with the GraphPad Prism 7.0 software. A difference of $p<0.05$ was considered statistically significant. DIANA-miRPath v3.0 software was used for assessment of miRNA regulatory roles and the identification of controlled pathways (30).

\section{RESULTS}

\section{OLE Reduces the SAA-Driven Release of Pro-Inflammatory Cytokines and Chemokines From HCAEC}

Treatment of HCAEC with OLE alone or in combination with SAA did not decrease the viability of HCAEC when compared to untreated cells (data not show). Inflammatory chemokines and cytokines play an important role in recruiting inflammatory cells and sustaining inflammation in chronic inflammatory diseases. To mimic the inflammatory milieu in the vasculature of patients with an activated systemic inflammatory response, we stimulated HCAEC with SAA (1000 nM or $12 \mathrm{mg} / \mathrm{l})$. While high concentrations of SAA are commonly reached in the circulation of patients with infections, inflammatory and autoimmune diseases or trauma (31), chronically elevated low levels of SAA can already cause atherosclerosis (11). Stimulation of HCAEC with SAA significantly increased the release of IL-6, IL-8, and MIF (Figures 1A,B). Treatment with OLE reduced this SAAinduced release of IL-6 and IL-8 in a dose-dependent manner (Figures 1A,B). While $1 \mathrm{mg} / \mathrm{ml}$ OLE significantly decreased the release of IL-6 into supernatants of the SAA-stimulated HCAEC, the release of IL-8 returned to baseline levels. Additionally, similar effects of OLE were observed on the SAA-driven release of $\mathrm{GRO} \alpha$, although significant changes were not observed (most probably due to large differences in the basal production of GRO $\alpha$ in HCAEC). SAA-driven release of MIF was not affected (Figures 1C,D). Overall, this suggests that OLE can modulate the expression of a subset of the SAA-induced proinflammatory genes.

\section{OLE Alters the mRNA Expression of SAA-Induced E-Selectin in HCAEC}

SAA significantly increased the expression of E-selectin mRNA in HCAEC, whereas VCAM-1 mRNA was up-regulated on average 4-fold above baseline with a notable variation between the donors (significance not reached) (Figures 2A,B). SAA-driven upregulation of E-selectin mRNA returned to baseline in the presence of OLE (Figure 2B). Moreover, OLE significantly downregulated the constitutive expression of both E-selectin and VCAM-1 mRNAs (Figures 2A,B). While SAA strongly enhanced pro-inflammatory and pro-adhesive activities in HCAEC, it did not alter significantly the expression of MMP2, MMP9 and mRNAs (Figures 2C,D).

\section{SAA-Induced NF- $\kappa$ B Phosphorylation Is Reduced by OLE}

The SAA-induced activation of gene expression coincided with the increase in the phosphorylation of NF- $\mathrm{B}$ p65 (Figure 3). $\mathrm{NF}-\kappa \mathrm{B}$ is the central transcription factor in the expression of pro-inflammatory genes including those coding for cytokines, chemokines, and adhesion molecules (32). The SAA-increased phosphorylation of NF-kB was decreased in the presence of OLE (Figure 3). This shows that OLE could exert its antiinflammatory and anti-adhesive effect also through modulation of NF- $\mathrm{kB}$ signaling.

\section{OLE Protects HCAEC From SAA-Induced and $\mathrm{H}_{2} \mathrm{O}_{2}$-Induced DNA Damage}

Oxidative stress occurs when the formation of free radicals increases or when the antioxidant capacity of a cell is decreased, leading to DNA damage (33). COMET assay is a sensitive method to measure DNA damage in cells (34), where the relative amount of DNA in the COMET tail indicates the frequency of DNA breaks. Our results demonstrated that under basal conditions, on average $58 \%$ of HCAEC exhibited no COMET tails (condition A), whereas only $8 \%$ of the SAA-treated HCAEC were without COMET tails (Figure 4A). While $0.5 \mathrm{mg} / \mathrm{ml}$ OLE largely mimicked the background control in category $\mathrm{A}$, a smaller percentage of cells, around 30\%, exhibited no COMET tails when treated with $1 \mathrm{mg} / \mathrm{ml} \mathrm{OLE} \mathrm{(Figure} \mathrm{4A).} \mathrm{Nevertheless,} \mathrm{the}$ treatment with $0.5 \mathrm{mg} / \mathrm{ml}$ and $1 \mathrm{mg} / \mathrm{ml}$ OLE decreased DNA damage in the SAA-treated HCAEC, with $38 \%$ and $40 \%$ of HCAEC, respectively, exhibiting no DNA damage (no COMET tails) (Figure 4A). This data shows that SAA induces DNA damage in HCAEC, which can be largely prevented in the presence of OLE. Furthermore, OLE decreased the susceptibility of HCAEC to oxidative DNA damage, induced by treating the cells with $3 \% \mathrm{H}_{2} \mathrm{O}_{2}$ (Figure $4 \mathbf{B}$ ). Less than $10 \%$ of untreated cells and none of the SAA-stimulated cells were without COMET 
A

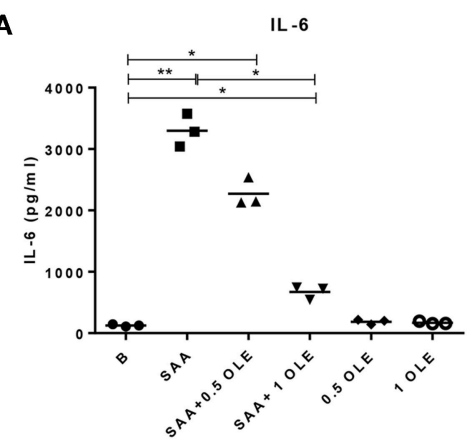

C

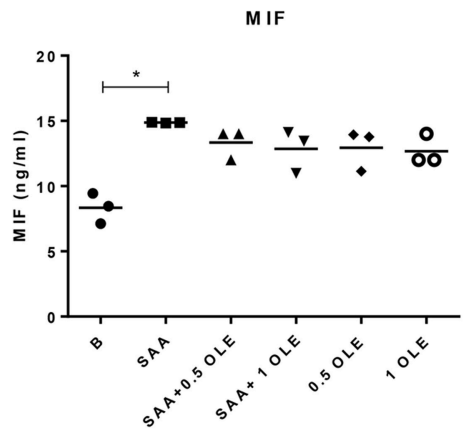

B

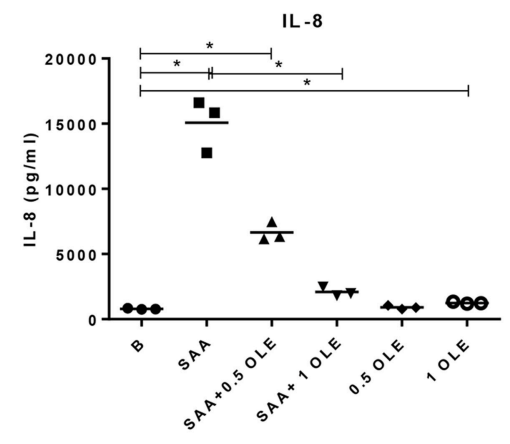

D

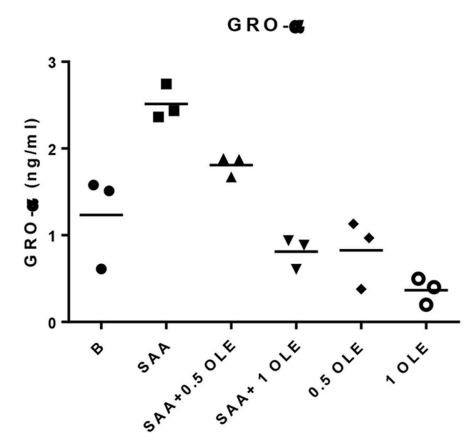

FIGURE 1 | OLE decreases SAA-driven release of pro-inflammatory cytokine IL-6 and chemokine IL-8 from HCAEC. The amount of IL-6 (A), IL-8 (B), MIF (C), and GRO- $\alpha$ (D) in cell culture supernatants were measured by ELISA. The mean of 3 biological replicates is shown. HCAEC were treated with OLE $(0.5 \mathrm{mg} / \mathrm{ml}, 1 \mathrm{mg} / \mathrm{ml})$ 45 min prior to SAA addition (1,000 nM, 24 h). Data was analyzed using RM one-way ANOVA test with Tukey's multiple comparison test ${ }^{*} p>0.05{ }^{* *} p>0.01$.

tails (no DNA damage) upon exposure to $\mathrm{H}_{2} \mathrm{O}_{2}$, however the percentage of HCAEC without COMET tails increased upon treatment with OLE (Figure 4B). Furthermore, in presence of $\mathrm{H}_{2} \mathrm{O}_{2}, 28 \%$ and $42 \%$ cells showed severe DNA damage (category E) in untreated and SAA-stimulated HCAEC, respectively. OLE alone or in the presence of SAA attenuated this damage (Figure 4B). Specifically, cells treated with OLE were evenly distributed in all categories, and the percentage of cells in category E was between 13 and 19\% (Figure 4B). Collectively, treatment with OLE protected HCAEC from oxidative DNA damage, while the treatment of HCAEC with SAA worsened the oxidative DNA damage.

\section{Expression of the SAA-Induced miR-146a and Let-7e Is Altered by OLE}

MicroRNA networks play a key role in regulating proinflammatory cell responses, as well as endothelial dysfunction. However, the expression and function of microRNAs during the SAA-driven endothelial activation remains largely unknown. Scarce evidence exists showing that OLE affects the microRNA profiles (35). To explore the alteration in microRNA networks during the SAA-driven endothelial activation, we measured the expression of miR-146a, let-7e, and let-7g with roles in inflammation (36) (Figures 5A-C). These measurements showed that SAA significantly increased the expression of miR-146a and OLE ameliorated the SAA-driven induction of miR-146a (Figure 5A) and let-7e (Figure 5B). The effects of SAA on the expression of let-7g (Figure 5C), however, were not changed from untreated HCAEC. Analysis of genes targeted with miR146a and mirR-let-7e [using $\gg$ Diana $\ll$ tool mirPath v3 (30)] showed significant association with Toll like receptor signaling ( $p=0.005, \mathrm{n}$ of genes targeted is 9 ), NF-kappa B signaling ( $p=0.009$, number of genes targeted is 6 , Figure 5D), ErbB signaling pathway ( $p=0.02$, number of genes targeted is 7) and Cell cycle ( $p=0.03$, number of genes targeted is 11) KEGG pathways (37).

\section{DISCUSSION}

Our study provides novel data on the positive effects of olive leaf extract on the human coronary artery endothelium ex vivo. We show that OLE decreases levels of IL-6, IL-8 released protein and E-selectin mRNA in HCAEC in response to the endogenous inflammatory SAA, likely by reducing the SAA-driven phosphorylation of NF- $\mathrm{B}$ p65. Furthermore, OLE changes the SAA-driven miR-146a and let-7e expression and decreases SAA-induced and $\mathrm{H}_{2} \mathrm{O}_{2}$-induced oxidative DNA damage in HCAEC, indicating protection at multiple levels. Using HCAEC in vitro cell culture model, we mimicked OLE's actions on the endothelial cell function. However, certain effects could be elucidated further only by using in vivo models or interventional human studies, e.g., the effects of OLE on the cholesterol/triglyceride profiles $(18,26)$. 
A

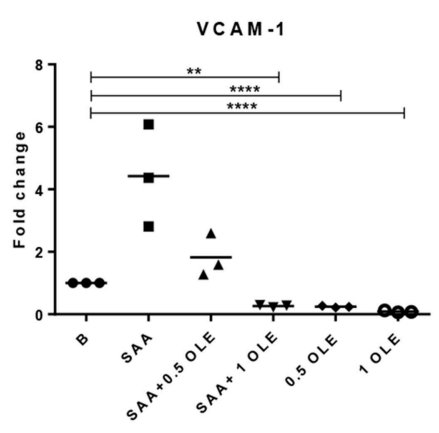

C

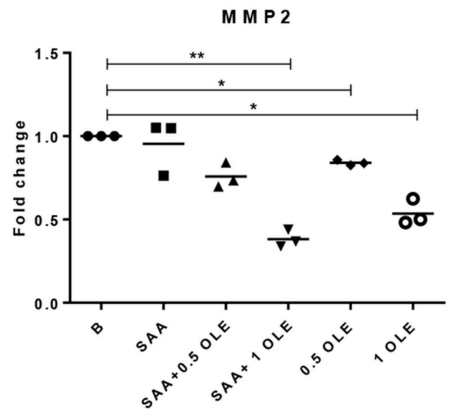

B

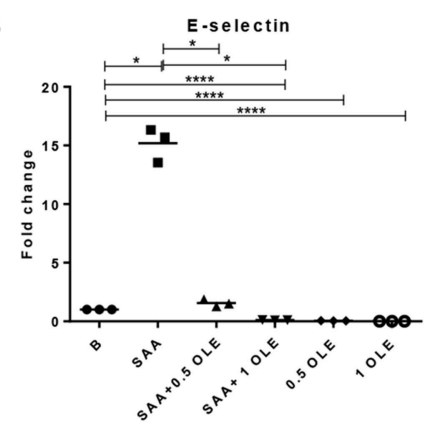

D

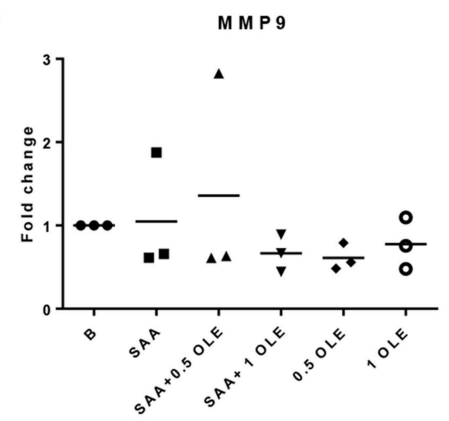

FIGURE 2 | OLE decreases mRNA expression of adhesion molecules and MMP2 in HCAEC. The expression of VCAM-1 (A), E-selectin (B), MMP2 (C), and MMP9 (D) mRNA was determined by qPCR. Mean of 3 biological replicates is shown. HCAEC were treated with OLE $(0.5 \mathrm{mg} / \mathrm{ml}, 1 \mathrm{mg} / \mathrm{ml}) 45 \mathrm{~min}$ prior to SAA addition $(1,000 \mathrm{nM}, 24 \mathrm{~h})$. Data was analyzed using RM one way ANOVA test with Tukey's multiple comparison test ${ }^{\star} p>0.05{ }^{{ }^{*}} p>0.01 ;{ }^{* \star \star \star} P<0.0001$.

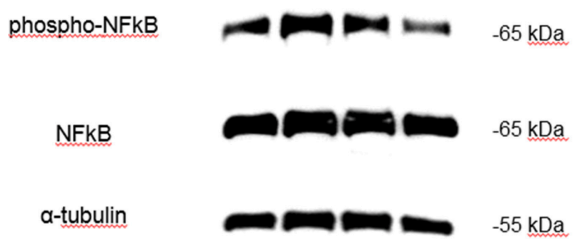

B SAA SAA+OLE1 OLE1
B

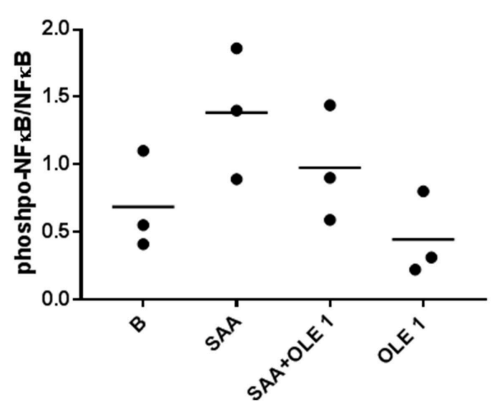

FIGURE 3 | OLE attenuates SAA-induced phosphorylation of NF-kB. (A) Western blot shows phosphorylation of NF-kB in HCAEC pretreated with OLE for $1 \mathrm{~h}$ and then treated with OLE \pm SAA for $1 \mathrm{~h}(\mathrm{SAA} 1,000 \mathrm{nM}$, OLE $1 \mathrm{mg} / \mathrm{ml}$ ). Representative blot of $n=3$ biological replicates. (B) Densitometry analysis of protein bands was carried out using the Fusion FX software (Vilber Lourmat), $n=3$ biological replicates. For quantification of Western blots, the levels of phosphorylated NF-kB were normalized to the levels of total NF-кB. Equal amounts of protein were loaded per gel pocket. $\alpha$-tubulin was used as a loading control.

Our results are in line with the human intervention study of olive leaf supplementation, which identified NF- $\kappa$ B as a central biological factor influenced by OLE (27). Similarly, a dietary intervention study showed that contrary to butter and walnut meals extra virgin olive oil did not elicit the phosphorylation of NF- $\kappa$ B in PBMC from healthy individuals (38). Moreover, OLE inhibited the phosphorylation of NF- $\kappa \mathrm{B}$ and AP-1 in HUVEC and Raw264 macrophages (24, 28). Polyphenol compounds, such as oleuropein attenuated the phosphorylation of NF-кB in mouse models of ileum ischemia/reperfusion (39) and spinal cord injury (40). Overall, this suggests that active ingredients of OLE might have a therapeutic potential in regulating the activity of NF- $\kappa$ B.

We show that OLE decreases the SAA-induced release of IL-6 and attenuates the SAA-driven IL- 8 and pro-adhesive E-selectin in HCAEC. Moreover, OLE decreased the basal expression of both pro-adhesive molecules, VCAM-1 and Eselectin, in HCAEC. All these molecules are critical effectors in the atherosclerosis process (41-44). The attenuation of proinflammatory responses causes a mediator-specific effect in 
A

B
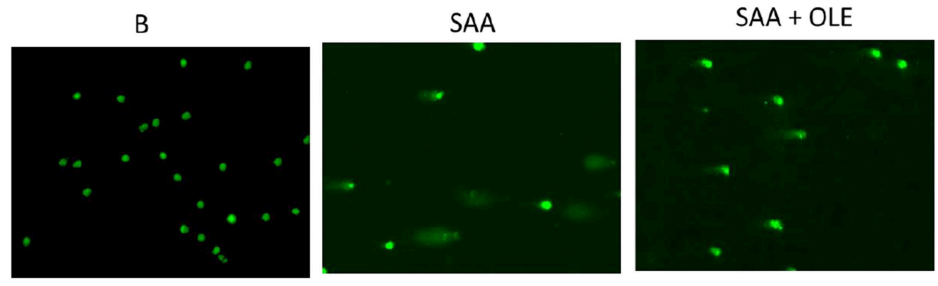

B

B

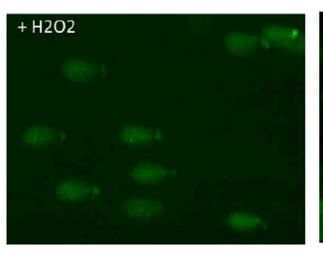

SAA

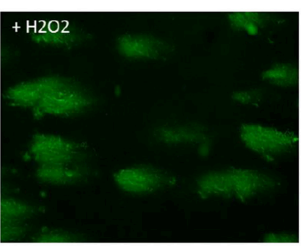

SAA + OLE

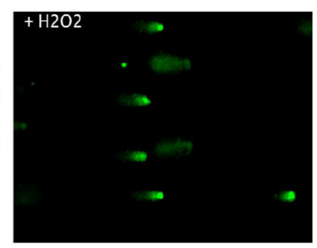

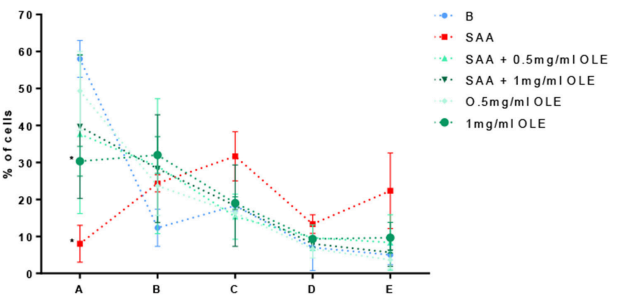

SAA + 0.5 g g/mIOLE

SAA + $1 \mathrm{mg} / \mathrm{m}$ IOLE $1 \mathrm{mg} / \mathrm{mlOLE}$

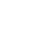

$\sqrt{2+2}$

\section{更}


A

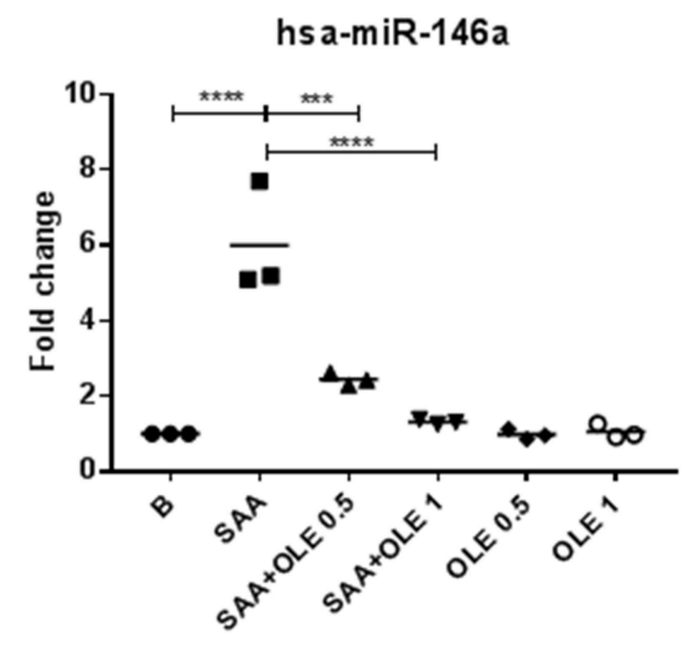

C

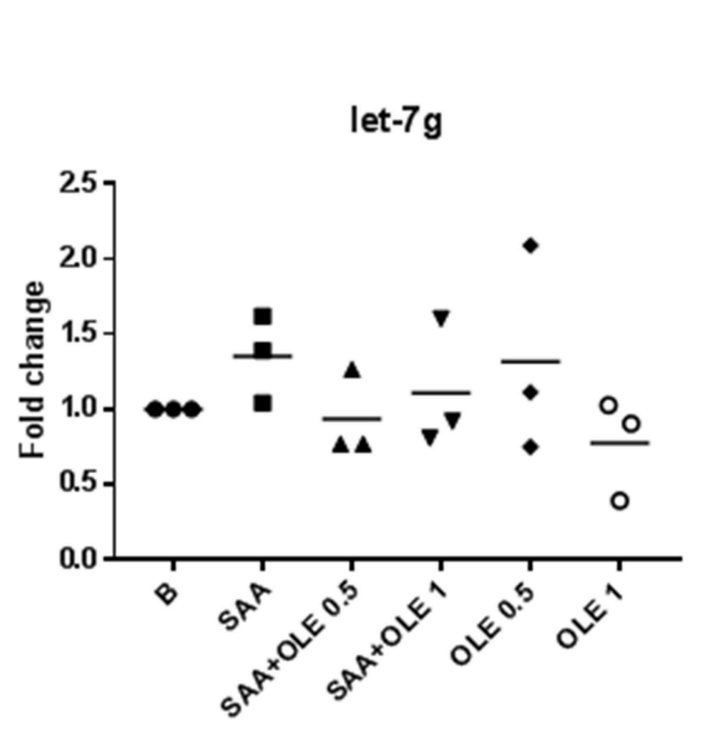

B

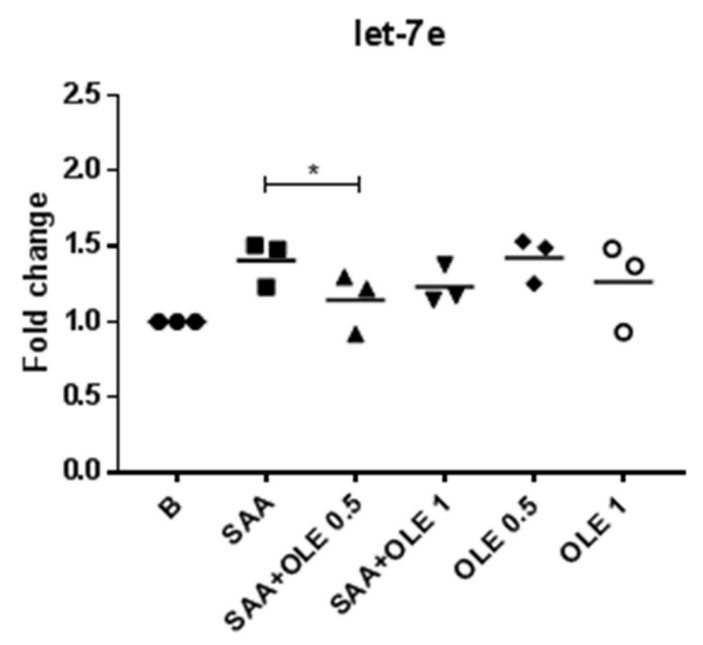

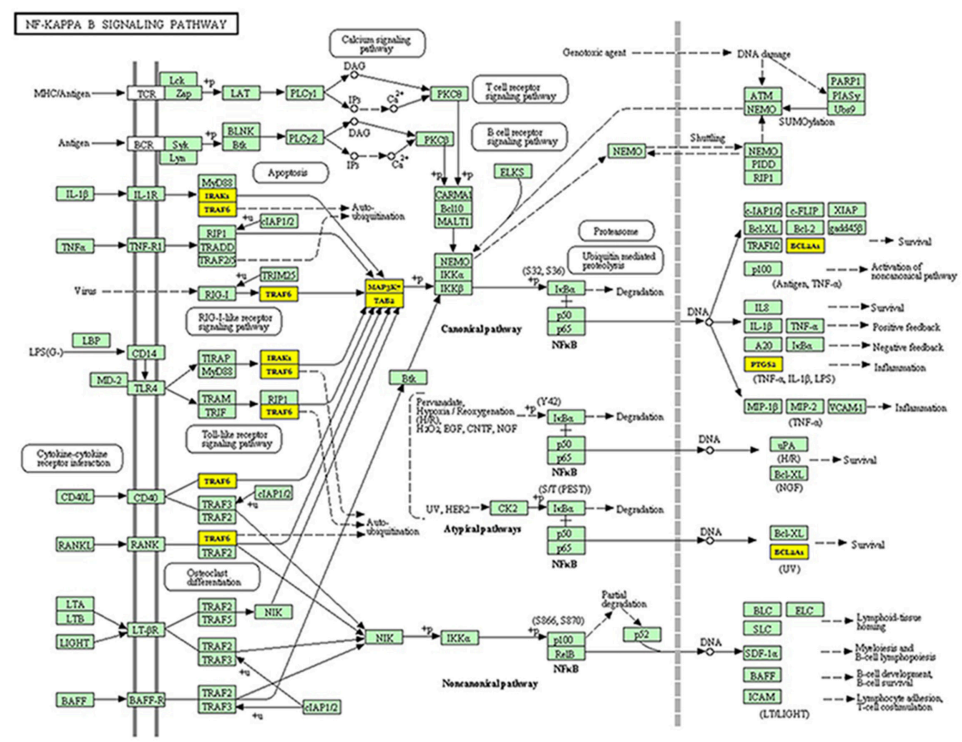

FIGURE 5 | OLE regulates SAA-induced miR-146a and let-7e. (A-C) represent fold changes of mRNA expression levels of miR-146a, let-7e and let-7g, respectively. The mean is shown of 3 biological replicates. Data was analyzed using RM one way ANOVA test with Tukey's multiple comparison test $p$-values are shown as follows ${ }^{\star} p>0.05,{ }^{\star \star \star} P<0.001,{ }^{\star \star \star \star} P<0.0001$. (D) miR-146 and let-7e functional analysis showed significant influence on KEGG NF-kB signaling pathway $(p=0.009)$ (37) with 6 predicted target genes (marked yellow).

substantial DNA damage induction vs. slightly increased or stable viability $(56,57)$. This could be due to, on the one hand, SAA inflammatory events causing DNA damage in HCAEC, while on the other hand, viability might reflect the implication of elevated SAA in multiple types of cancers (e.g., esophageal squamous cell, ovarian, breast, lung, renal, and gastric) with increasing levels correlating with severity of cancer stages (58). The question then emerges whether SAA downregulates expression of genes, such as p53, thus elevating cell survival and cell cycle progression, which could be addressed in the future.

At the microRNA level, we show that SAA increases the expression of microRNA146a and let-7e in HCAEC, while OLE significantly attenuates these SAA-induced effects. The activation of NF- $\kappa B$ induces the expression of microRNA-146a, which acts as a negative feedback regulator of NF- $\mathrm{KB}$ via targeting TRAF6 
and IRAK1/2. This controls the NF-кB transcriptional activity in the presence of excessive pro-inflammatory stimulation (36). Contrary to microRNA-146a, let-7e promotes the activation of NF- $\kappa$ B by inhibiting the expression of I $\mathrm{B} \beta$ in endothelial cells (59). Thus, OLE could fine-tune SAA-driven activity of NF- $\kappa$ B by altering cellular microRNA networks (60).

In regard to the DIANA-miRPath v3 data (30) combining target prediction algorithms, with manually curated miRNA:gene interaction datasets to chart miR-146a and let-7e targets, the following genes and their involvement in processes most likely to be affected are, among others: TLR2 pathway (TLR2, TAB2, AKT2, JUN, TRAF6, STAT1, IRF7, IRAK1, MAP3K7), NF-кB pathway (TAB2, TRAF6, PTGS2, BCL2A1, IRAK1, MAP3K7), ErbB pathway (GSK3B, EGFR, STAT5B, AKT2, JUN, CDKN1A, ABL1) and cell cycle (GSK3B, CCNB1,CDC25B, SMAD4, RBL1, CDC23, CDKN1A, PRKDC, MDM2, ABL1, CDC25A). Among these genes, several are implicated in survival (BCL2A1, EGFR, STAT5B), ubiquitin-mediated proteolysis (TAB, TRAF6, IRAK1, MAP3K7, CDC23), anti-viral effects (IRF7), metabolism (AKT2, GSK3B). Interestingly, the cell cycle genes included both promoting (e.g., CDC23, CDC25A), as well as regulating (e.g., CDKN1A, CCNB1) genes of the cell cycle. In cells in general, it would be interesting to determine whether SAA downregulates PRKDC (elevating p53) and/or upregulates MDM2 (attenuating p53). While in silico analysis tools and applications, such as miRPath provide support to research, in vitro experimentation will further be necessary to confirm specific gene involvement.

Possible mechanisms of SAA activity could include changes in gene expression of pro-inflammatory cytokines, epigenetic events (e.g., miRNA-related), as well as induced reactive oxygen, nitrogen species, which may, in turn cause damage to cellular components (e.g., DNA), leading to chronic acceleration of chronic vascular disease, with OLE providing a counterbalance to these processes. In line with this, our data suggests that OLE exhibits multiple protective actions that could prevent

\section{REFERENCES}

1. Lakota K, Artenjak A, Cučnik S, Brguljan J, Cegovnik B, Salobir B, et al. Atherogenesis, inflammation and autoimmunity - an overiew. In: Parthasarathy S, editor. Atherogenesis. Rijeka: InTech (2012). p. 187-202.

2. Hua S, Song C, Geczy CL, Freedman SB, Witting PK. A role for acutephase serum amyloid A and high-density lipoprotein in oxidative stress, endothelial dysfunction and atherosclerosis. Redox Rep. (2009) 14:18796. doi: 10.1179/135100009X12525712409490

3. Obici L, Raimondi S, Lavatelli F, Bellotti V, Merlini G. Susceptibility to AA amyloidosis in rheumatic diseases: a critical overview. Arthritis Rheum. (2009) 61:1435-40. doi: 10.1002/art.24735

4. Krishack PA, Bhanvadia CV, Lukens J, Sontag TJ, De Beer MC, Getz GS, et al. Serum amyloid A facilitates early lesion development in Ldlr/- Mice. J Am Heart Assoc. (2015) 4:e001858. doi: 10.1161/JAHA.115.0 01858

5. Getz GS, Krishack PA, Reardon CA. Serum amyloid A and atherosclerosis. Curr Opin Lipidol. (2016) 27:531-5. doi: 10.1097/MOL.00000000000 00331

6. Mezaki T, Matsubara T, Hori T, Higuchi K, Nakamura A, Nakagawa I, et al. Plasma levels of soluble thrombomodulin, C-reactive protein, and serum or attenuate pro-inflammatory activation, influence vascular remodeling via modulation of MMP2 expression and may prevent DNA damage in the coronary arterial endothelium. This suggests that olive leaf extract, or its derivatives, might have athero-protective actions also in vivo, which would need to be further explored in the future.

\section{AUTHOR CONTRIBUTIONS}

$\mathrm{BB}, \mathrm{KL}$, and MF-B designed the experiments, acquired, and analyzed the data, and wrote the manuscript. KL, BB, TK, TJ, KM-P, DT, and PŽ performed the experiments. DT, LŽ, and BS-P obtained OLE and advice on COMET. SS-S, SČ and OD coordinated the study. All authors participated in critical discussion of the data and drafting the manuscript. All authors have seen and approved the manuscript and its contents and are aware of the responsibilities connected to authorship.

\section{FUNDING}

The study was supported by the Slovenian Research Agency ARRS with the bilateral project BU-RS/16-17-019, the National Research Program \#P3-0314 and Be The Cure (BTCure).

\section{ACKNOWLEDGMENTS}

The authors would like to thank A. Zupanic and S. Hernandez for assistance in editing this manuscript.

\section{SUPPLEMENTARY MATERIAL}

The Supplementary Material for this article can be found online at: https://www.frontiersin.org/articles/10.3389/fcvm. 2019.00056/full\#supplementary-material amyloid A protein in the atherosclerotic coronary circulation. Jpn Heart J. (2003) 44:601-12. doi: 10.1536/jhj.44.601

7. Thompson JC, Jayne C, Thompson J, Wilson PG, Yoder MH, Webb N, et al. A brief elevation of serum amyloid A is sufficient to increase atherosclerosis. $J$ Lipid Res. (2015) 56:286-93. doi: 10.1194/jlr.M054015

8. Johnson BD, Kip KE, Marroquin OC, Ridker PM, Kelsey SF, Shaw LJ, et al. Serum amyloid A as a predictor of coronary artery disease and cardiovascular outcome in women: the National Heart, Lung, and Blood Institute-Sponsored Women's Ischemia Syndrome Evaluation (WISE). Circulation. (2004) 109:726-32. doi: 10.1161/01.CIR.0000115516. 54550.B1

9. Katayama T, Nakashima H, Takagi C, Honda Y, Suzuki S, Iwasaki Y, et al. Prognostic value of serum amyloid A protein in patients with acute myocardial infarction. Circ J. (2005) 69:1186-91. doi: 10.1253/circj. 69.1186

10. Sack GH Jr. Serum amyloid A - a review. Mol Med. (2018) 24:46. doi: 10.1186/s10020-018-0047-0

11. Ridker PM. Inflammation, atherosclerosis, and cardiovascular risk: an epidemiologic view. Blood Coagul Fibrinol. (1999) 10 (Suppl 1):S9-12.

12. Lakota K, Mrak Poljšak K, Rozman B, Kveder T, Tomšič M, Sodin-Šemrl S. Serum amyloid A activation of inflammatory and adhesion molecules in 
human coronary artery and umbilical vein endothelial cells. Eur J Inflam. (2007) 5:73-81. doi: 10.1177/1721727X0700500203

13. Cervelli T, Borghini A, Galli A, Andreassi MG. DNA damage and repair in atherosclerosis: current insights and future perspectives. Int J Mol Sci. (2012) 13:16929-44. doi: 10.3390/ijms131216929

14. Zhang BK, Lai X, Jia SJ. Epigenetics in atherosclerosis: a clinical perspective. Discov Med. (2015) 19:73-80.

15. Khyzha N, Alizada A, Wilson MD, Fish JE. Epigenetics of atherosclerosis: emerging mechanisms and methods. Trends Mol Med. (2017) 23:33247. doi: 10.1016/j.molmed.2017.02.004

16. Jacinto TA, Meireles GS, Dias AT, Aires R, Porto ML, Gava AL, et al. Increased ROS production and DNA damage in monocytes are biomarkers of aging and atherosclerosis. Biol Res. (2018) 51:33. doi: 10.1186/s40659-018-0182-7

17. Boss A, Bishop KS, Marlow G, Barnett MP, Ferguson LR. Evidence to support the anti-cancer effect of olive leaf extract and future directions. Nutrients. (2016) 8:E513. doi: 10.3390/nu8080513

18. Wang L, Geng C, Jiang L, Gong D, Liu D, Yoshimura H, et al. The antiatherosclerotic effect of olive leaf extract is related to suppressed inflammatory response in rabbits with experimental atherosclerosis. Eur J Nutr. (2008) 47:235-43. doi: 10.1007/s00394-008-0717-8

19. Hassen I, Casabianca H, Hosni K. Biological activities of the natural antioxidant oleuropein: exceeding the expectation - a mini-review. J Funct Foods. (2015) 18:926-40. doi: 10.1016/j.jff.2014.09.001

20. Rigacci S, Stefani M. Nutraceutical properties of olive oil polyphenols. An itinerary from cultured cells through animal models to humans. Int J Mol Sci. (2016) 17:E843. doi: 10.3390/ijms17060843

21. Kim SW, Hur W, Li TZ, Lee YK, Choi JE, Hong SW, et al. Oleuropein prevents the progression of steatohepatitis to hepatic fibrosis induced by a high-fat diet in mice. Exp Mol Med. (2014) 46:e92. doi: 10.1038/emm.2014.10

22. Dekanski D, Janicijeic-Hudomal S, Tadic V, Markovic G, Arsic I, Mitrovic D. Phytochemical analysis and gastroprotective activity of an olive leaf extract. J. Serbian Chem. Soc. (2009) 74:367. doi: 10.2298/JSC0904367D

23. Giner E, Recio MC, Rios JL, Giner RM. Oleuropein protects against dextran sodium sulfate-induced chronic colitis in mice. J Nat Prod. (2013) 76:111320. doi: $10.1021 / \mathrm{np} 400175 \mathrm{~b}$

24. Ryu SJ, Choi HS, Yoon KY, Lee OH, Kim KJ, Lee BY. Oleuropein suppresses LPS-induced inflammatory responses in RAW 264.7 cell and zebrafish. J Agric Food Chem. (2015) 63:2098-05. doi: 10.1021/jf505894b

25. Lockyer S, Corona G, Yaqoob P, Spencer JP, Rowland I. Secoiridoids delivered as olive leaf extract induce acute improvements in human vascular function and reduction of an inflammatory cytokine: a randomised, double-blind, placebo-controlled, cross-over trial. Br J Nutr. (2015) 114:7583. doi: $10.1017 /$ S0007114515001269

26. Lockyer S, Rowland I, Spencer JPE, Yaqoob P, Stonehouse W. Impact of phenolic-rich olive leaf extract on blood pressure, plasma lipids and inflammatory markers: a randomised controlled trial. Eur J Nutr. (2017) 56:1421-32. doi: 10.1007/s00394-016-1188-y

27. Boss A, Kao CH, Murray PM, Marlow G, Barnett MP, Ferguson LR. Human intervention study to assess the effects of supplementation with olive leaf extract on peripheral blood mononuclear cell gene expression. Int J Mol Sci. (2016) 17:E2019. doi: 10.3390/ijms17122019

28. Carluccio MA, Siculella L, Ancora MA, Massaro M, Scoditti E, Storelli $\mathrm{C}$, et al. Olive oil and red wine antioxidant polyphenols inhibit endothelial activation: antiatherogenic properties of Mediterranean diet phytochemicals. Arterioscler Thromb Vasc Biol. (2003) 23:622-9. doi: 10.1161/01.ATV.0000062884.69432.A0

29. Cabarkapa A, Zivkovic L, Zukovec D, Djelic N, Bajic V, Dekanski D, et al. Protective effect of dry olive leaf extract in adrenaline induced DNA damage evaluated using in vitro comet assay with human peripheral leukocytes. Toxicol in vitro. (2014) 28:451-6. doi: 10.1016/j.tiv.2013. 12.014

30. Vlachos IS, Zagganas K, Paraskevopoulou MD, Georgakilas G, Karagkouni D, Vergoulis T, et al. DIANA-miRPath v3.0: deciphering microRNA function with experimental support. Nucleic Acids Res. (2015) 43:W4606. doi: 10.1093/nar/gkv403

31. De Buck M, Gouwy M, Wang JM, Van Snick J, Opdenakker G, Struyf $S$, et al. Structure and expression of different serum amyloid a (saa) variants and their concentration-dependent functions during host insults.
Curr Med Chem. (2016) 23:1725-55. doi: 10.2174/0929867323666160418 114600

32. Pahl HL. Activators and target genes of Rel/NF-kappaB transcription factors. Oncogene. (1999) 18:6853-66. doi: 10.1038/sj.onc.1203239

33. Birben E, Sahiner UM, Sackesen C, Erzurum S, Kalayci O. Oxidative stress and antioxidant defense. World Allergy Organ J. (2012) 5:919. doi: 10.1097/WOX.0b013e3182439613

34. Liao W, Mcnutt MA, Zhu WG. The comet assay: a sensitive method for detecting DNA damage in individual cells. Methods. (2009) 48:4653. doi: 10.1016/j.ymeth.2009.02.016

35. Tezcan G, Tunca B, Bekar A, Budak F, Sahin S, Cecener G, et al. Olea europaea leaf extract improves the treatment response of GBM stem cells by modulating miRNA expression. Am J Cancer Res. (2014) 4:572-90.

36. Tahamtan A, Teymoori-Rad M, Nakstad B, Salimi V. Anti-inflammatory MicroRNAs and their potential for inflammatory diseases treatment. Front Immunol. (2018) 9:1377. doi: 10.3389/fimmu.2018.01377

37. Kanehisa M, Furumichi M, Tanabe M, Sato Y, Morishima K. KEGG: new perspectives on genomes, pathways, diseases and drugs. Nucleic Acids Res. (2017) 45:D353-61. doi: 10.1093/nar/gkw1092

38. Bellido C, Lopez-Miranda J, Blanco-Colio LM, Perez-Martinez P, Muriana FJ, Martin-Ventura JL, et al. Butter and walnuts, but not olive oil, elicit postprandial activation of nuclear transcription factor kappaB in peripheral blood mononuclear cells from healthy men. Am J Clin Nutr. (2004) 80:148791. doi: $10.1093 /$ ajcn/80.6.1487

39. Campolo M, Di Paola R, Impellizzeri D, Crupi R, Morittu VM, Procopio A, et al. Effects of a polyphenol present in olive oil, oleuropein aglycone, in a murine model of intestinal ischemia/reperfusion injury. J Leukoc Biol. (2013) 93:277-87. doi: 10.1189/jlb.0712317

40. Impellizzeri D, Esposito E, Mazzon E, Paterniti I, Di Paola R, Bramanti P, et al. The effects of a polyphenol present in olive oil, oleuropein aglycone, in an experimental model of spinal cord injury in mice. Biochem Pharmacol. (2012) 83:1413-26. doi: 10.1016/j.bcp.2012.02.001

41. Papadopoulou C, Corrigall V, Taylor PR, Poston RN. The role of the chemokines MCP-1, GRO-alpha, IL-8 and their receptors in the adhesion of monocytic cells to human atherosclerotic plaques. Cytokine. (2008) 43:1816. doi: 10.1016/j.cyto.2008.05.009

42. Shaposhnik Z, Wang X, Lusis AJ. Arterial colony stimulating factor-1 influences atherosclerotic lesions by regulating monocyte migration and apoptosis. J Lipid Res. (2010) 51:1962-70. doi: 10.1194/jlr.M005215

43. Hartman J, Frishman WH. Inflammation and atherosclerosis: a review of the role of interleukin-6 in the development of atherosclerosis and the potential for targeted drug therapy. Cardiol Rev. (2014) 22:14751. doi: $10.1097 / C R D .0000000000000021$

44. Tousoulis D, Oikonomou E, Economou EK, Crea F, Kaski JC. Inflammatory cytokines in atherosclerosis: current therapeutic approaches. Eur Heart J. (2016) 37:1723-32. doi: 10.1093/eurheartj/ehv759

45. Pacheco YM, Bemudez B, Lopez S, Abia R, Villar J, Muriana FJ. Minor compounds of olive oil have postprandial anti-inflammatory effects. Br J Nutr. (2007) 98:260-3. doi: 10.1017/S0007114507701666

46. Perez-Jimenez F, Ruano J, Perez-Martinez P, Lopez-Segura F, Lopez-Miranda J. The influence of olive oil on human health: not a question of fat alone. Mol Nutr Food Res. (2007) 51:1199-208. doi: 10.1002/mnfr.200600273

47. Vacek TP, Rehman S, Neamtu D, Yu S, Givimani S, Tyagi SC. Matrix metalloproteinases in atherosclerosis: role of nitric oxide, hydrogen sulfide, homocysteine, and polymorphisms. Vasc Health Risk Manag. (2015) 11:17383. doi: 10.2147/VHRM.S68415

48. Rothfuss A, O’Donovan M, De Boeck M, Brault D, Czich A, Custer L, et al. Collaborative study on fifteen compounds in the rat-liver Comet assay. Mutat Res. (2010) 702:40-69. doi: 10.1016/j.mrgentox.2010.07.006

49. Langie SAS, Azqueta A, Collins AR. The comet assay: past, present, and future. Front Genet. (2015) 6:266. doi: 10.3389/fgene.2015.00266

50. Turagam MK, Vuddanda V, Verberkmoes N, Ohtsuka T, Akca F, Atkins D, et al. Epicardial left atrial appendage exclusion reduces blood pressure in patients with atrial fibrillation and hypertension. J Am Coll Cardiol. (2018) 72:1346-53. doi: 10.1016/j.jacc.2018.06.066

51. Lorenzo Y, Costa S, Collins AR, Azqueta A. The comet assay, DNA damage, DNA repair and cytotoxicity: hedgehogs are not always dead. Mutagenesis. (2013) 28:427-32. doi: 10.1093/mutage/get018 
52. Azqueta A, Collins AR. The comet assay: a sensitive and quantitative method for analysis of DNA damage. In: Meyers RA, editor. Encyclopedia of Analytical Chemistry: Applications, Theory and Instrumentation. Chichester: John Wiley (2011). doi: 10.1002/9780470027318.a9192

53. Ge J, Chow DN, Fessler JL, Weingeist DM, Wood DK, Engelward BP. Micropatterned comet assay enables high throughput and sensitive DNA damage quantification. Mutagenesis. (2015) 30:11-9. doi: 10.1093/mutage/geu063

54. Weingeist DM, Ge J, Wood DK, Mutamba JT, Huang Q, Rowland EA, et al. Single-cell microarray enables high-throughput evaluation of DNA double-strand breaks and DNA repair inhibitors. Cell Cycle. (2013) 12:907-15. doi: $10.4161 /$ cc. 23880

55. Townsend TA, Parrish MC, Engelward BP, Manjanatha MG. The development and validation of EpiComet-Chip, a modified high-throughput comet assay for the assessment of DNA methylation status. Environ Mol Mutagen. (2017) 58:508-21. doi: 10.1002/em.22101

56. Filippin-Monteiro FB, De Oliveira EM, Sandri S, Knebel FH, Albuquerque RC, Campa A. Serum amyloid A is a growth factor for 3T3-L1 adipocytes, inhibits differentiation and promotes insulin resistance. Int J Obes. (2012) 36:1032-9. doi: 10.1038/ijo.2011.193

57. Yu N, Zhang S, Lu J, Li Y, Yi X, Tang L, et al. Serum amyloid A, an acute phase protein, stimulates proliferative and proinflammatory responses of keratinocytes. Cell Prolif. (2017) 50:e12320. doi: 10.1111/cpr.12320
58. Zhou J, Sheng J, Fan Y, Zhu X, Tao Q, He Y, et al. Association between serum amyloid A levels and cancers: a systematic review and meta-analysis. Postgrad Med J. (2018) 94:499-507. doi: 10.1136/postgradmedj-2018-136004

59. Lin Z, Ge J, Wang Z, Ren J, Wang X, Xiong H, et al. Let-7e modulates the inflammatory response in vascular endothelial cells through ceRNA crosstalk. Sci Rep. (2017) 7:42498. doi: 10.1038/srep42498

60. Vasa-Nicotera M, Chen H, Tucci P, Yang AL, Saintigny G, Menghini R, et al. miR-146a is modulated in human endothelial cell with aging. Atherosclerosis. (2011) 217:326-30. doi: 10.1016/j.atherosclerosis.2011.03.034

Conflict of Interest Statement: The authors declare that the research was conducted in the absence of any commercial or financial relationships that could be construed as a potential conflict of interest.

Copyright (c) 2019 Burja, Kuret, Janko, Topalović, Živković, Mrak-Poljšak, Spremo-Potparević, Žigon, Distler, Čučnik, Sodin-Semrl, Lakota and FrankBertoncelj. This is an open-access article distributed under the terms of the Creative Commons Attribution License (CC BY). The use, distribution or reproduction in other forums is permitted, provided the original author(s) and the copyright owner(s) are credited and that the original publication in this journal is cited, in accordance with accepted academic practice. No use, distribution or reproduction is permitted which does not comply with these terms. 